\title{
One of the Revelations for Mo Yan's Winning of Nobel Prize: The Significance and Limitation of Mysterious Writing in Contemporary Chinese Literature
}

\author{
Taiyun Xiao \\ School of Literature, Southwest University, Chongqing, China. \\ Email: 275585765@qq.com
}

Received 15 May 2014; revised 17 June 2014; accepted 18 July 2014

Copyright (C) 2014 by author and Scientific Research Publishing Inc.

This work is licensed under the Creative Commons Attribution International License (CC BY). http://creativecommons.org/licenses/by/4.0/

(c) (i) Open Access

\begin{abstract}
Since the 1990s, the relaxed politic and literary environment has left space for mysterious writing, and a series of mystery novels gain Chinese domestic awards for literature, such as the White Deer Plain, Red Poppies and Right bank of the Argun that won the Mao Dun prize which is the highest honor of novel writings in China. Furthermore, Mo Yan's winning of the Nobel Prize for Literature indicates that mysterious writing is in the ascendant in contemporary Chinese literature. The contents of this paper are as follows: firstly, the definitions of mystery and mysterious writing are defined, and traces of mysterious writing in ancient Chinese literature and its development in the context of contemporary literature are surveyed; secondly, the manifestations of mysterious writing and its multiple aesthetic dimensions are investigated; thirdly, the aesthetic significance and value connotations of mysterious writing are displayed; Finally, the reflection and planning for the limitations and way out of mysterious writing are illustrated. The results of this paper are: Mysterious writing is consistently existent in the history of Chinese literature with various manifestations; Mysterious writing broadens the scope of literary aesthetics, constructs a special aesthetic style and aesthetic effect, and enriches the value forms and the quality state of contemporary literature. But there are also some disadvantages of Mysterious writing and we should look at it from a dialectical perspective.
\end{abstract}

\section{Keywords}

Contemporary Chinese Literature, Mysterious Writing, Aesthetic Form, Aesthetic Significance, Value and Significance, Value Connotation, Writing Limitation 


\section{Introduction}

In 2012, Mo Yan's winning of the Nobel Prize for Literature greatly inspired Chinese people, and effectively alleviated people's anxiety from the thought that it was too difficult to win Nobel Prizes, which led Chinese literature into a virtuous and healthy development track, and boosted Chinese people to have a calm reflection of contemporary literature. The award words that the Swedish Nobel Committee gave to Mo Yan's were: “he blends hallucinatory realism, folk legends, history and contemporary together”1. From these words, we can find that mysterious writing is one of the most important factors for his winning of Nobel Prize for Literature. Coincidentally, the award words for Alai's novel Red Poppies, which won the Mao Dun prize for literature were "the lightly touch of magical color enhances the strength of artistic expression”, ; and the award words of Chi Zijian's work Right Bank of the Argun which also won the Mao Dun prize for literature were that "this work respects for life, reverences for nature, and adheres to the faith”3. These three award-winning works are just a fraction of all mysterious writings in contemporary literature, but they are good enough to represent one of today's colorful literary phenomena: the tendency to write mysterious literary is in the ascendant. Therefore, the questions which we need to have a reflection are: what's the significance of mysterious writing of Chinese contemporary literature? What makes it worthy of being valued? What's the limitation? And what are the countermeasures?

\section{The Definition of Mysterious Writing and Its Evolution in Chinese Literature}

If we say that mystery is a person's perception of the unpredictable world, a kind of soul tremor made by the incomprehensible and the ineffable cosmic phenomenon, and a cognition way of human to grasp the world and understand life, mysterious writing is the poetic construction and representational characterization of the esoteric and mysterious contents in literature, and a bridge built by the writers for communicating with the world. What mysterious writing conveys to us are a sense of unity of men and God, a sense of peace and emptiness that space and time elapsed, a sense of awe for fear, and a kind of unspeakable pleasure or a sense of tranquility. Mysterious writing characterized as integrality, life influence, anti-logic, transcendence, poetry, creativity and other features, and it aims to perceive the world and life through image.

China is an ancient oriental country with strong flavor of mysticism. The mysterious culture in China has a long tradition and rich forms. On cultural perspective, mystery is manifested as "the unity of Heaven and men”; On ontological perspective, mystery is manifested as "fortune and Palmistry, unity of Tao (the invisible things: such as spirit, psychology and so on) and Qi (the visible things)”; On epistemological perspective, mystery is manifested as "unknown” (on nature), and "the Prophet” (acquired learning); On methodological perspective, mystery is manifested as “comprehension”. People continuously attach great importance to mysterious writing, and we can find mysterious writings in Chinese literature such as the ancient mythology, the mythical stories in Age of Fragmentation, legends in Tang dynasty, scripts of story-telling in Song dynasty, the four famous novels in the Ming and Qing dynasty. During May Fourth Movement (a patriotic movement in 1919), people advocated science and enlightenment, and mystical literature were suppressed, but there were still some writers created mysterious works, such as Liang Zongdai created some mystical poetries, and Shen Congwen created some mysterious country novels. After the founding of The People's Republic of China, some Chinese statesmen advocated destroying the "four dregs of society", but mysterious writing still did not disappear during the period of time, and we can still find the traces of mysterious writing in some classic novels, such as Snowy Forest (Qu, 1964). Even during the Cultural Revolution, mysterious narrative still survived in some novels, such as $A$ Pair of Embroidered Shoes (Kuang, 1980). After the reform and opening up of China, mysterious writing experienced a strong trend of recovery, then showed a full bloom around the 1990s, and reached its peak in this new century. For example, Han Shaogong attaches a great importance on folk legends, jokes in folk songs, customs and habits handed down from the ancestors in southern China; Jia Pingwa concerns on the mysterious anomalies like ghosts culture in central China; in the novels made by one pioneer woman writer-Can Xue, we can find that she keeps a keen interest on mysticism. It can be said that mysterious literature is one importance part of the literature in new era, or we can say that the recovery of mysterious writing is an irresistible trend which accords

\footnotetext{
${ }^{1}$ http://culture.ifeng.com/huodong/special/2012nuobeierwenxuejiang/content-3/detail_2012_10/11/18190507_0.shtml ${ }^{2}$ http://baike.baidu.com/link?url=BvaNqDAgiyK18cmWHjk4zT0u-lMyvzZa2e9tZzXVpB7e1wshrit6t6iiIglkNQ3 QpSnXe8fxnfunuQ1aS8g $\underline{\mathrm{Wa}}$

${ }^{3}$ http://www.baike.com/wiki/\%E3\%80\%8A\%E9\%A2\%9D\%E5\%B0\%94\%E5\%8F\%A4\%E7\%BA\%B3\%E6\%B2\%B3\%E5\%8F\%B3\%E5\%B 2\%B8\%E3\%80\%8B
} 
with the development regular of literature and works in concert with the literary tradition of mystical writing. This phenomenon demonstrates the importance of literary aesthetic properties, broadens the aesthetic boundaries of literature, enhances the aesthetic space of literature, and ensures the poetic character and spiritual tolerance of contemporary literature. These can be considered as the significance of mysterious writing on literary history.

\section{The Manifestations of Mysterious Writing}

Mysterious writing is embodied in colorful and various forms in the works of contemporary mystery writers and multiple dimensions of aesthetic appreciation are needed when we investigate it. From the narrative perspective, mysterious writing can be divided into two kinds, the first one is the mystery of narrative form, such as the circular cycle in Mo Yan's work Life and Death Are Wearing Me Out (Mo, 2006); the second one is the mystery of narrative kernel, such as the mysterious fate of Wang Qiyao in Wang Anyi's work Everlasting Regret (Wang, 1995). From the perspective of contents, mysterious writing can be classified into the following dimensions: the dimension of myths and legends, for example, Su Tong makes a modern expression of the myth about Meng Jiangnv in his work A Myth of Meng Jiangnv (Su, 2006); the dimension of religious divinity, for example, Hai $\mathrm{Zi} \mathrm{(1990)} \mathrm{has} \mathrm{a} \mathrm{metaphysical} \mathrm{comprehension} \mathrm{of} \mathrm{religion} \mathrm{in} \mathrm{his} \mathrm{poem} \mathrm{series} \mathrm{Sun} \mathrm{(include} \mathrm{seven} \mathrm{poems);} \mathrm{the} \mathrm{di-}$ mension of folk beliefs, for example, in Han Shao-gong's work Maqiao Dictionary (Han, 1996), he searches for the witchcraft beliefs in everyday life and reveals the cultural backwardness of folk mysticism from the perspective of scientific rationality; the dimension of Phantom and ghost, for example, in Chen Zhongshi's work White Deer Plain (Chen, 1993), he uses the case that Xiao'e borrows the body for resurrection to accuse the hypocrisy and corruption of Confucian ethical codes; the dimension of soothsaying, for example, in Alai's work Settled (Alai, 1998), he combines the mysterious premonition with dreams, and decodes the long traditional mysticism in Tibetan culture; the dimension of totem and taboo, for example, in God Sandalwood Tree which contains 24 poems (Nan, 1996), the author Nan Yongqian whose nationality is Korean makes a Poetic representation of the original mystical totem culture in his nationality, and so forth. From the perspective of expression themes, mysterious writing can be divided into the following aspects: the writing of mysterious phenomena, for example, Jia Pingwa describes the original mystery of customs in Qinba area (now known as Shaanxi province) and restores the originality of life in his novel Shangzhou series; the rendering of mystical experience, in Yu Hua's work Inexorable doom (Yu, 1988), he makes an abnormal deduction of the prophetical fate and the mysterious death experiences which indicates the salvation of hopeless life; the expression of mysterious consciousness, for example, Chi Zi-jian expresses his animist consciousness, and advocates that both people and all things have the similar wisdom in Right Bank of the Argun (Chi, 2005).

From the point of view manifestations, in addition to the aforementioned means such as witchcraft, divination, dreams, prophecy, ghosts, original customs, myths and legends to describe the mysterious phenomena and convey "explicit mysterious writing" of inner mysterious consciousness, contemporary writers focus on the mystery of inner pursuit, and pay attention to the dialectic " introspective mystery writing” of soul. There is a kind of divinity in the innermost of everyone's heart. Mysterious soul is a magical haven of Contemplation and meditation, other then, mysterious soul can foster us to see the great things in the tiny things, can help us get eternal enlightenment at one moment, can guide us to understand the mysteries of the universe and the essence of life, and can lead us to feel the eternal moments, the secluded and profound realm. In Zhang Wei's work September Fables (Zhang, 1993), in order to respond to the mysterious call of the heart, the young man in the small seaside fishing village runs consistently to pursue the anterior faint light in the wilderness, and the work aims to convey people's pursuit of ideals through "Fables” construction; in Shi Tiesheng's work Life as String (Shi, 1994), the old and young blind men played the sorrow of life by soul, and the purpose is just to in search of the hope and the courage to live, and to make the soul to settle down; in Ge Fei's work Moment of truth (Ge, 2004), the protagonist valiantly chases the Utopia soul, the humanity and the utopian ideals of revolutionary. Soul is the core element of spirit, and the most mysterious source of the human mind. The ultimate purpose of pursuing spirit is to pursue the transcendence of soul, and "only the soul can hold on to the lapel of the god" (Liu, 1999). Closing your flesh eyes, opening our eyes of soul, and keeping your eyes of soul away from the hustle and bustle world, and thus returning to ego self, returning to the innermost soul, and observing the truth by the eyes of soul, and in another word, this is the purport of introspective mysterious writing.

\section{The Aesthetic Significance of Mysterious Writing}

As one category of aesthetic, mysterious writing manifested with various themes broadens the realm of Chinese 
literature since late 20th Century, and the aesthetic significance of mysterious writing can be displayed as follow: Firstly, on the perspective of aesthetic realm, mysterious writing finds new aesthetic resources, creates a new aesthetic dimension, develops the aesthetic concept of literature, enriches the aesthetic means of literature, thus broadens the aesthetic space of literature. During the Cultural Revolution for seventeen years, realism has been long-dominated Chinese literature world for the overwhelming position of politics, and mysterious writing was severely suppressed, while root-seeking literature and Avant-garde literature which have strong mystical natures widened people's aesthetic visions, expanded people's aesthetic thinking, changed and improved the aesthetic ideas and aesthetic tastes of people. Since the 1990s, mysterious writings play a leading role in contemporary Chinese literature for their deepness and darkness, creating a colorful and prosperous literature world.

Secondly, Mysterious writing not only rediscovers some attractive aesthetic resources and explores a meaningful aesthetic dimension, but its own poetry and spirituality bring us a kind of fantasy and romantic aesthetic art styles of contemporary literary, which can creates a hazy, subtle and profound aesthetic effect and give us a fresh aesthetic experience. For example: 1), the beauty of fantastic imagination. In Mo Yan's work Red Sorghum (Mo, 1987), when "my grandmother" is dying, her flying soul gives us a kind of psychedelic beauty, and Mo Yan brings us a kind of beautiful and amazing scene by his fanciful and unrestrained imagination; 2), a kind of weird and strange beauty, in the vanguard novels, the writers such as Ma Yuan and Tashi Dawa prefer to confusing narrative of plots, and through the narrative of the confusion of life and the long-distance experience of fear, the difficulty and length of aesthetic are increased, resulting in a kind of strange, wonder and extraordinary effect; 3) the implication beauty of mystery, in Jia Pingwa's work The Stories of the Taibai Mountain (Jia,1989), the author gets resources from the animistic nature, dawns inspiration from folk legends, creates a kind of imagery brewing atmosphere and grasps the life through mysterious writing, which results in multiple implications which can not only increase the width and depth of literature aesthetic, but also enhance the readability of the work. All of these can be considered the aesthetic sense of mysterious writing.

\section{The Value Connotation of Mysterious Writing}

Mystery, as an epistemological category, has been irreversibly replaced by scientism now, but as a special mindset, it can help us to generate an awareness of the universe and have a reflection of our own. Therefore, Mystery has its own ideological significance. Firstly, on the perspective of value choice, mysterious writing overturns the traditional "real" concept. The mysterious writing writers strongly pursue the values, such as the nature of history. As a means of value breakthrough, mysterious writing is one part of the multiple dimensional culture value structure of contemporary literary. Therefore, mysterious writing enriches the value forms and the value positions of contemporary literary. Secondly, on the perspective of value positions, resources of many contemporary mysterious writings are from folk life, and mysterious writings writers with Pioneer spirit aim to deconstruct the main writing forms and decompose grand narratives, and pay attention to the feelings of folk people. Thirdly, on the perspective of value connotation, contemporary literature shows in-depth experience and expressive performance of mystery, which reveals the multiple connotations of life, humanity, national character, Chinese culture, and symbolic expression. Value connotation can be embodied by the following four aspects: First, the decode and reflection of life, for example, in Can Xue's novels, she describes the nightmarish and animal-like "real" existence of people to construct a fable expression of the traumatic life of the suffered people after the Cultural Revolution and the alienated life under the rule of technology, and in Chi Zijian's work Right Bank of the Argun, she describes a mysterious and invigorating world where people are looking for "the totem of life", and construct a poetic existence of life to combat the desertification life status of modern people; Second, the dissection and reflection of humanity, for example, in Jia Pingwa's work The Wasted (Jia, 1993), he focuses on highlighting the depraved humanity of modern people in his mystical imagination that human and cattle share the similar wisdom and can communicate with each other. Otherwise, in Shi Tiesheng's work Life as Strings, he hopes to arouse the dignity of humanity through the description of the mysterious and dignified life of the disabilities, and then declares the meaning of being alive. Third, the illumination and reflection of Chinese national character, for example, in Mo Yan's works Sandalwood Penalty (Mo, 2005) and The Republic of Wine (Mo, 1993), he magically renders the tales about excruciation and "eat babies", which can mercilessly reveal and whip the depravities and numbness of the Chinese people, and vice versa, in his work Red Sorghum and Big Breasts and Wide Hips (Mo, 1996), he describes a invigorating life existence of "my" grandparents in the background of legendary folk life in northern China, which have a sharp contrast with the weakness of modern national character, and he aims to revive the health and powerful vitality of original life; Fourth, the interpre- 
tation and reflection of Chinese culture, for example, in Wang Anyi’s work Little Bao Zhuang (Wang, 1988), he describes the mysterious flood legends and in Chen Zhongshi's work White Deer Plain, he describes the folklore that the white deer is the demon, and both of these magical expressions described in these two works can help us to have a good understanding of the advantages and disadvantages of Confucian ethics, and have a reflection of its changes in modern society, and then guide us to explore and reconstruct its modern way out in modern society.

\section{The Limitations and Way Out of Mysterious Writing}

Since 1985, mysterious writing has being developed for 30 years. Even though we can gain a lot of successful experiences from mysterious writing, which can ensure the good spirit taste of contemporary literature, the culture direction and enrich the artistic styles, but there are also some limitations of mysterious writing: some mysterious writing writers do not take reality into consideration and make good use of mystery as the supporter to reflect life and society, but regard mystery as a shelter for escaping from life, society and history, which result in the depreciation of works. When some contemporary female writers make use of mystical experiences in their novels to express the living predicament of women or even the entire human beings, they put too much emphasis on self-perception and self-expression, and confine themselves in the small world of individual; some writers repeatedly apply mysterious writings in their works for creating a kind of mystery, resulting in the lost of the unique and beauty of mysterious writing, which can radically depreciate the aesthetic value and the philosophical value of works, for example, some writers just regard mysterious writings as a mean which services for the religion purposes in their works, and restrains themselves into religious sermons. In general, all of these shortcomings are worthy of having a good reflection.

How can mysterious writing win the appreciation both on its beauty and quality? Firstly, broaden life experiences. Writers should go into the life of folk people, experience their life and make good use of the experiences in works because these life experiences can ensure the quality and value of works. Secondly, cultivate the internal soul. Writers should attentively get in touch with mysteries, feel mysteries and sublimate mysteries, and then, the nimbus and the depth of mysterious writing can be expressed. Thirdly, promote spirit and value elevation. The pursuit of art is endless, and only if the writers promote their mental shackles can mysterious writings create a kind of great atmosphere and grand realm.

\section{Conclusions}

Since the 1980s, the mysterious writing has been experiencing a period of revitalization and inheritance, which contributes much to the prosperity of Contemporary Chinese Literature. Since the late 20th century, mysterious writing of Chinese literature has gradually become popular and deeper in the breadth and depth: before the 1990s, the mysterious writing of Contemporary Chinese Literature emphasized on the performance of "explicit mystery", such as Root-seeking literature that mainly focused on the performance of the mysterious phenomena; avant-garde literature mainly emphasized on the narrative form of mystery. After the 1990s, the scope of mysterious writing was expanded greatly, for example, it was expended to the dimension of religious divinity, and dimensions of totem and taboo, etc. In addition to this, the proportion of "introspective mystery" is gradually increased in mysterious writing of contemporary Chinese literature, and the depth of its performance is also strengthened, for example, Mo Yan perfectly combines mysterious novels with contemporary Chinese social reality, which creates a sense of national allegory. Mysterious writing adds poetic and spiritual effects to contemporary Chinese literature, creating a fantasy, romantic and deep aesthetic atmosphere. Mysterious writing also has been valuable and significant for it is not only a kind of rebellious writing method, but also reveals the deep meaning of Chinese people's life, humanity, ethnic and Chinese culture, therefore, the crucial role of mysterious writing in the construction of Contemporary Chinese culture cannot be ignored.

The finds of this paper can be concluded as follows: Firstly, mysterious writing of contemporary Chinese literature becomes thriving and prosperous for the relaxed control of ideology in China; conversely, mysterious writing promotes people to be more open-minded, and then helps people to establish a social environment with open and pluralistic values; Secondly, writing from mysterious dimension really has widen the horizons of Chinese writers, and helped them to create the flourishing literature since the late 20th century, which indirectly contribute much to Mo Yan's winning of the Nobel Prize for Literature; Thirdly, mysterious writing of contemporary Chinese literature also has its limits, therefore, Chinese writers should improve their spiritual realms from 
life experiences and apperception.

\section{References}

Alai (1998). Red Poppies. Beijing: People’s Literature Publishing House.

Chen, Z. S. (1993). White Deer Plain. Beijing: People’s Literature Publishing House.

Chi, Z. J. (2005). Right Bank of the Argun. Beijing: Beijing October Art Publishing House.

Ge, F. (2004). Moment of Truth. Shenyang: Chunfeng Literature and Art Publishing House.

Hai, Z. (1990). Poetry Anthology of Hai Zi: Land (Sun • Land Articles). Shenyang: Chunfeng Literature and Art Publishing House.

Han, S.-G. (1996 ). Maqiao Dictionary. Beijing: Writers Publishing House.

Jia, P. W. (1989). The Stories of the Taibai Mountain. Shanghai Literature, 8, 10-15.

Jia, P. W. (1993). The Wasted. Beijing: Beijing Publishing House.

Kuang, H. W. (1980). A Pair of Embroidered Shoes. Shanghai: Shanghai People’s Fine Arts Publishing House.

Liu, X. F. (1999). Heavy Body. Shanghai: Shanghai People’s Publishing House.

Mo, Y. (2006). Life and Death Are Wearing Me Out. Beijing: Writers Publishing House.

Mo, Y. (1987). Red Sorghum. Beijing: PLA Literature and Art Publishing House.

Mo, Y. (2005). Sandalwood Penalty. Beijing: Writers Publishing House.

Mo, Y. (1993). The Republic of Wine. Changsha: Hunan Literature and Art Publishing House.

Mo, Y. (1996). Big Breasts and Wide Hips. Beijing: Writers Publishing House.

Nan, Y. Q. (1996). God Sandalwood Tree. Shenyang: Liaoning Nationalities Publishing House.

Qu, B. 1964). Snowy Forest. Beijing: People’s Literature Publishing House.

Shi, T. S. (1994). Life as String. Nanjing: Jiangsu Literature and Art Publishing House.

Su, T. (2006) A Myth of Meng Jiangnv. Chongqing: Chongqing Publishing House

Yu, H. (1988). Inexorable Doom. The Harvest, 6, 20-28.

Wang, A. Y. (1995). Everlasting Regret. Beijing: Writers Publishing House.

Wang, A. Y. (1988). Little Bao Zhuang. Shanghai: Shanghai Literature and Art Publishing House.

Zhang, W. (1993). September Fables. Shanghai: Shanghai Literature and Art Publishing House. 
Scientific Research Publishing (SCIRP) is one of the largest Open Access journal publishers. It is currently publishing more than 200 open access, online, peer-reviewed journals covering a wide range of academic disciplines. SCIRP serves the worldwide academic communities and contributes to the progress and application of science with its publication.

Other selected journals from SCIRP are listed as below. Submit your manuscript to us via either submit@scirp.org or Online Submission Portal.
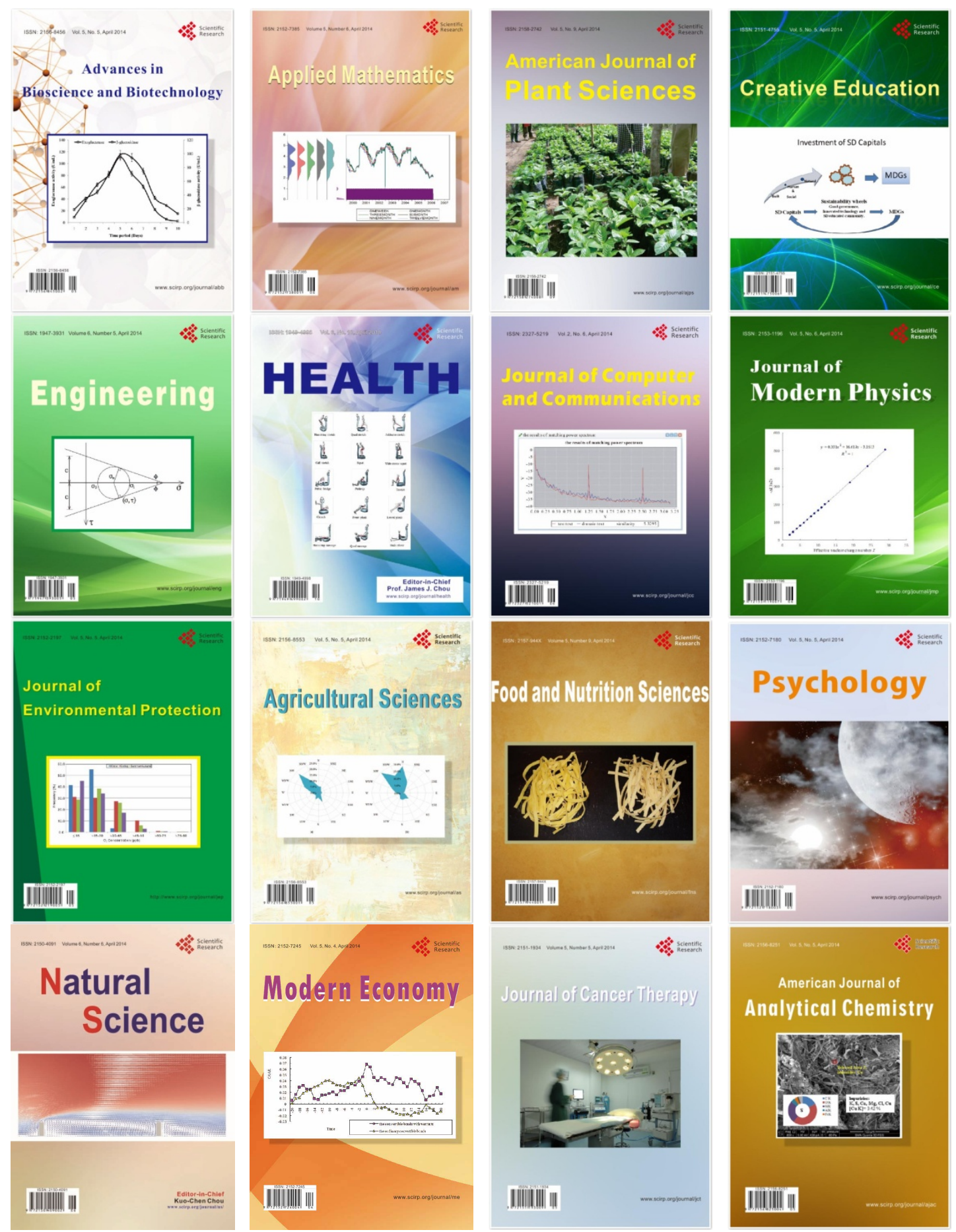